\title{
Effect of Debt Knowledge on the Indebtedness of Employees in the Formal Sector in Kenya
}

\author{
Morris Irungu Kariuki ${ }^{1}$, Fredrick Ogilo ${ }^{2, *}$, Cyrus Iraya Mwangi ${ }^{3}$ \\ ${ }^{1}$ School of Human Resources and Development, Jomo Kenyatta University of Agriculture and Technology, Kenya \\ ${ }^{2}$ School of Business, University of Nairobi, Mombasa Campus, Kenya \\ ${ }^{3}$ School of Business, University of Nairobi, Nairobi Campus, Kenya
}

Copyright $\odot 2016$ by authors, all rights reserved. Authors agree that this article remains permanently open access under the terms of the Creative Commons Attribution License 4.0 International License

\begin{abstract}
The study sought to establish the relationship between debt knowledge and indebtedness in Kenya. Positivism paradigm was used in this study. The study adopted a cross sectional and correlational descriptive research design. The study targeted about 2.4 million employees in the formal sector. Three stage sampling was done, first, cluster sampling and then, stratified sampling and finally random sampling. The study used primary data collected by use of self-administered questionnaires. A pilot test of the questionnaire was conducted on 40 respondents to check its validity and reliability. 1000 questionnaires were circulated. Of the returned, 581 questionnaires were considered usable. Cronbach's alpha for likert type items was found reliable (over 0.7). Data analysis used IBM SPSS statistics 21 for descriptive and correlation analysis. Further, OLS Multiple regression models were used to examine the relationships between the independent variable and the dependent variable. The findings reveal that debt experience has a significant effect on indebtedness. Results also found that aggregated debt literacy only explain a mere $9.8 \%$ of respondent's indebtedness. The study will help to buttress economic theories of borrowing. Further the government, policy makers, employers and scholars will benefit from the findings of the study. Future research should explore the effect of dimensions like debt attitude and financial socialization on indebtedness. Further, debt literacy for individuals in the informal sector need to be related to their indebtedness while the lenders' perspective need to be sought.
\end{abstract}

Keyword Debt Knowledge, Indebtedness, Formal Sector, Financial Socialization

\section{Introduction}

Like corporation, individual strive for rational financial decisions in the areas of savings, investment and borrowing.
These decisions are important for aggregate consumption and financial stability (Cynamon \& Fazzari, [6]). The problem especially with borrowing is when the individual borrows disproportionately to his or her means leading to over-indebtedness (Liv, [17]). Indebtedness has been defined in several ways. For instance, Gathergood [12]; Liv [17] and Schicks [25] have used a qualitative measure where the respondents were requested to indicate the level of financial disstress on a likert scale. This measure is subjective since it is based on the borrowers' judgement. Other researchers have used ratio analysis such as; ratio of total debt to gross income (Malaysia, [22]), debt repayment to gross income (Liv, [17]) and total debt to assets (Frade \& Abreu, [10]) among others.

Debt knowledge refers to abstract skills, education and current information about management of financial obligation possessed by an individual. Therefore a person is debt knowledgeable when he understands the basic concepts of money management and specifically debt finance (Huston, [14]; Loke \& Hageman, [18]).According to ILO[15] formal sector refers to the section of the economy which provided jobs that are subject to national legislation, income tax, social protection or entitlement to benefits such as annual leave, group life and medical insurance, pension and gratuity. The sector have written rules, agreement and job description where employees are required to work known and fixed hour for agreed fixed salaries.

\section{Objective}

The objective of the study was to explain the relationship between debt knowledge and indebtedness of formal sector employees in Kenya.

\section{Hypothesis}

There is no significant relationship between debt 
knowledge and indebtedness of formal sector employees in Kenya.

\section{Methodology}

The study was conducted between March and May 2016. The data was collected via self-administered questionnaire from a target of 2.4 million working Kenyan residents. To arrive at the final respondents a three stage sampling was done, First the entire population was clustered into provinces. Threee provinces (coast, central and Nairobi) were purposeviely selected while finally respondents were randomly targeted. Using Cochran's 1977 formulae, questionnaires were administered to a sample of 1000 respondents.. Data analysis was carried out using SPSS version 21.

The study collected a number of socio-economic characteristics of the employee such as age, gender, and marital status, region of workstation, family size and income. Debt knowledge was operationalised using three approaches. First, seven questions to assess abstract skill and financial information were used. The questions were aimed at testing basic numeracy skills and required basic financial information and simple reasoning they did not require a calculator. Second, respondents were requested to rank their debt knowledge in a scale of 1 to 7. Third, six likert scale questions were used to assess the debt education and training of the respondents. The study used a positivism research philosophy, since the study was based on both existing theory and hypothesized relationship. A cross-sectional, correlational descriptive research design was used to accept the hypothesized relationship.

Three dimensions of indebtedness were used. First, Debt Service Ratio (DSR) was computed using total debt repayment and gross disposable income. Second, Debt Income Ratio (DIR) was computed using total outstanding loan and gross disposable income. Finally, aggregate indebtedness was found by multiplication of DSR and DIR.

The model which was tested was:

$$
Y=\beta_{0}+\beta_{1} X_{1}+\varepsilon_{i}
$$

Where:

$\mathrm{Y}=$ indebtedness (ID)

$\boldsymbol{\beta}_{0}=$ level of ID in the absence of debt knowledge

$\beta_{1}=$ intercept for debt knowledge

$\mathrm{X}_{1}=$ debt knowledge

$\varepsilon_{i}=$ error term

The test of significance was performed using correlation and $\mathrm{R}^{2}$ values from the regression tests.

\section{Results}

The questionnaire was pretested with 40 employed,
Master of Business Administration (MBA), first years students from the University of Nairobi, Mombasa Campus. Cronbach's alpha was used to measure the reliability of the data collection instrument (internal consistency) where the emphasis was on all likert scale questions in the questionnaire. Debt education and training questions had Cronbach's alpha of 0.852 which is good. Cronbach's alpha of less than 0.5 is unacceptable, between 0.5 and 0.6 is poor, between 0.6 and 0.7 is questionable, between 0.7 and 0.8 is acceptable, between 0.8 and 0.9 is considered good while over 0.9 is excellent (George \& Mallery, [13]). The targeted respondents in the study were employees working in the formal sector in Kenya. 1,000 questionnaires were distributed; only 648 were returned. Of the returned questionnaires, 67 were rejected because they were not satisfactorily complete. Similar studies have sampled the same number of respondents. For example, Bhushan and Medury [3] by structured questionnaire, 516 respondents were realized. Another related study by Schicks [25] which measured the over-indebtedness of micro-borrowers in Ghana conducted an in-depth survey of 531 micro debtors. Yet another study by Zakaria, Jaafar \& Marican [28] determined the relationship between financial behaviour and financial position of urban households in Malaysia used 916 questionnaires. While Van Ooijen and Van Rooij [26] in their study on mortgage risks; debt literacy and financial advice finally settled on sample of 459 households.

ANOVA results showed that there exists a significant ( $p$-value $=0.000)$ difference in educational levels of those reading financial articles. This supports Van Ooijen and Van Rooij [26] who found that the financial literate consulted a large number of information sources such as financial magazines, newspapers and internet. Those who need the financial articles least therefore read them.

Table 1. ANOVA- Debt education

\begin{tabular}{ccccc}
\hline & F & Sig. & Pearson Corr. & Sig. \\
\hline Sector & 3.216 & 0.000 & -0.230 & 0.000 \\
Occupation & 2.654 & 0.001 & 0.234 & 0.000 \\
Marital Status & 1.972 & 0.018 & -0.179 & 0.000 \\
Level of Education & 2.285 & 0.005 & 0.176 & 0.000 \\
Housing Category & 2.824 & 0.000 & 0.091 & 0.032 \\
Level of income & 1.723 & 0.048 & 0.136 & 0.001 \\
\hline
\end{tabular}

Results in Table 1 established that there was significant (p-values < 0.05) relationship between, first, sector of the respondents and debt education levels with those in private sector more knowledgeable. Second, respondents in the financial, insurance and professional occupation were found to be the most knowledge $($ mean $=3.73)$.

Third, respondents who are single had the highest debt education trailed by widow or widower category. As expected, those with high education have high debt knowledge. The most indebted respondents are mortgagees; coincidentally, they are also the most debt knowledgeable while the owner-occupiers are the least debt knowledgeable. 
It is also not surprising that the high-income group is the most debt knowledgeable because more often salaries are directly related to educational achievements. A study by Ajzerle, Brimble \& Freudenberg[1] found the least financially literate were those with low education, unemployed, unskilled, earning less than $\$ 20,000$ p.a., single, young (18 to 24 years) and the elderly (over 70 years).

Table 2. ANOVA- Debt training

\begin{tabular}{ccccc}
\hline & F & Sig. & Pearson Corr. & Sig \\
\hline Sector & 5.641 & 0.000 & -0.333 & 0.000 \\
Occupation & 3.835 & 0.000 & 0.323 & 0.000 \\
Gender & 1.322 & 0.190 & 0.127 & 0.000 \\
Level of education & 3.045 & 0.000 & 0.188 & 0.000 \\
Level of income & 1.387 & 0.165 & 0.189 & 0.000 \\
\hline
\end{tabular}

Results in Table 2 established that acquisition of debt knowledge can be associated significantly ( $\mathrm{p}$-value $<0.05$ ) with certain socio-economic characteristics. Respondents in private sector appear to have acquired debt training than those in public sector mean-wise. Further, those in financial, insurance and professional services occupations had more debt training. Men had a high degree of debt training than women. Those with high level of education had more debt training than their low education compatriots. Finally, there was a positive dependence between income and debt training with high-income group having the highest score. Unfortunately, attendance to training seminar is voluntary. Due to this, Lusardi [20] contends that only those who are interested and already aware of the value of debt training seminar attend them.

Table 3. ANOVA- Debt knowledge

\begin{tabular}{ccccc}
\hline & F & Sig. & Pearson Corr. & Sig, \\
\hline Sector & 2.970 & 0.000 & -0.301 & 0.000 \\
Occupation & 2.848 & 0.000 & 0.284 & 0.000 \\
Gender & 1.633 & 0.017 & 0.139 & 0.001 \\
Rural or urban & 2.206 & 0.000 & -0.156 & 0.000 \\
Level of income & 1.525 & 0.036 & 0.170 & 0.000 \\
\hline
\end{tabular}

Results in Table 3 found out that debt knowledge can be statistically associated (p-values $<0$ ) with some socio-economic characteristic such sector, occupation, gender, level of education and housing type. Consistent with Bhushan and Medury [3], respondents in the private sectors had a higher overall debt knowledge than those in public sector. Moreover, respondents working in the financial, insurance and professional services occupations had the highest mean. Those with the lowest mean were in the health profession. On the other hand, men had higher overall debt knowledge than women. Expectedly, those with higher academic qualification had a higher overall debt knowledge. Coincidentally, mortgagers had higher overall debt knowledge. Bhushan and Medury [3] found those in urban areas to have more financial knowledge. A study by Zuroni [29] found a significant relationship between credit card practices and educational levels while that to gender was not. The latter study concluded that working adults with high financial knowledge do not use their knowledge when using credit cards.

Table 4. Responses to compound interest question

\begin{tabular}{|c|c|c|c|c|c|}
\hline & & Frequency & Percent & Valid Percent & Cumulative Percent \\
\hline \multirow[t]{3}{*}{ Valid } & More than 150,000 & 437 & 75.2 & 79.0 & 79.0 \\
\hline & Exactly 150,000 & 82 & 14.1 & 14.8 & 93.9 \\
\hline & Total & 553 & 95.2 & 100 & \\
\hline Missing & 99 & 28 & 4.8 & & \\
\hline
\end{tabular}

In Table 4, it was found out that majority of the respondents $(79 \%)$ answered this question correct. This means they understand basic business mathematics on compound interest rate. However, this performance was worse compared with $85.1 \%$ scored in a similar question in a study by Disney and Gathergood [8].

Table 5. Responses to term structure question

\begin{tabular}{|c|c|c|c|c|c|}
\hline & & Frequency & Percent & Valid Percent & Cumulative Percent \\
\hline \multirow[t]{3}{*}{ Valid } & True & 154 & 26.5 & 28.3 & 28.3 \\
\hline & False & 389 & 67.0 & 71.7 & 100 \\
\hline & Total & 437 & 93.5 & 100.0 & \\
\hline \multirow[t]{2}{*}{ Missing } & 99 & 38 & 6.5 & & \\
\hline & & 581 & 100.0 & & \\
\hline
\end{tabular}

The responses in Table 5 relate to a query which tested the respondent's understanding of the relationship among installment amount, tenure of a loan and interest expense. The rule is that the higher the installment payable the less the tenure and interest payable. Majority of the respondents (71.5\%) answered this question correctly. 
Table 6. Responses to the guarantee question

\begin{tabular}{|c|c|c|c|c|c|}
\hline & & Frequency & Percent & Valid Percent & Cumulative Percent \\
\hline \multirow[t]{3}{*}{ Valid } & True & 428 & 72.8 & 78.2 & 78.2 \\
\hline & False & 118 & 20.3 & 21.8 & 100 \\
\hline & Total & 531 & 93.1 & 100 & \\
\hline \multirow[t]{2}{*}{ Missing } & 99 & 40 & 6.9 & & \\
\hline & & 481 & 100 & & \\
\hline
\end{tabular}

Results in Table 6 show s that SACCO loans are dominantly secured by personal guarantors. Responses in Table 6 relate to a query that tested the respondent's understanding of the need for sufficient guarantors in a loan contract. Majority of the respondents $(78.2 \%)$ answered this question correctly.

Table 7. Responses to the APR question

\begin{tabular}{|c|c|c|c|c|c|}
\hline & & Frequency & Percent & Valid Percent & Cumulative Percent \\
\hline \multirow[t]{3}{*}{ Valid } & True & 242 & 41.7 & 47.7 & 47.7 \\
\hline & False & 264 & 45.6 & 52.3 & 100 \\
\hline & Total & 506 & 87.3 & 100 & \\
\hline \multirow[t]{2}{*}{ Missing } & 99 & 75 & 12.7 & & \\
\hline & & 581 & 100 & & \\
\hline
\end{tabular}

Responses in Table 7 relates to the question that tested whether respondents have ever come across the term "Annual Percentage Rate" (APR); also called effective interest rate. Majority of the respondents (52.3\%) apparently are not conversant with APR. Worryingly, it would have been easy to answer this question correctly had respondents bothered to Google. However, the performance (47.7\%) is better when compared with results of a similar APR question in a study by Robb [24] where $33 \%$ of the respondents answered the question correctly.

Table 8. Responses to the Rule of 72 questions

\begin{tabular}{|c|c|c|c|c|c|}
\hline & & Frequency & Percent & Valid Percent & Cumulative Percent \\
\hline \multicolumn{2}{|c|}{2 years } & 88 & 15.1 & 16.4 & 16.4 \\
\hline \multicolumn{2}{|c|}{$2-5$ years } & 323 & 55.6 & 60.0 & 76.4 \\
\hline \multicolumn{2}{|c|}{$5-10$ years } & 115 & 19.8 & 21.4 & 97.8 \\
\hline \multicolumn{2}{|c|}{ More than 10 years } & 12 & 2.1 & 2.2 & 100 \\
\hline \multicolumn{2}{|c|}{ Total } & 538 & 92.6 & 100 & \\
\hline Missing & 99 & 43 & 7.4 & & \\
\hline \multicolumn{2}{|c|}{ Total } & 581 & 100 & & \\
\hline
\end{tabular}

Responses in Table 8 relates to the question that assessed whether the respondent understood simple interest, and especially the "rule of 72". The correct period is "2-5 years", precisely 3.6 years. Reviewing Table 9 show that majority of the respondents $(60 \%)$ answered this question correct. Surprisingly, this performance was better compared with previous studies by Lusardi and Tufano [20] and Disney and Gathergood [12] where the scores were 35.9\% and 25.1\% respectively using the same question. Yet it was overshadowed by performance of a similar question in a study by van Ooijen and van Rooij [26]; the score was $66.9 \%$. It is clearly apparent that respondents who answered incorrectly displayed rudimentary understanding of the concept of interest accrual.

Table 9. Responses to the debt repayment question

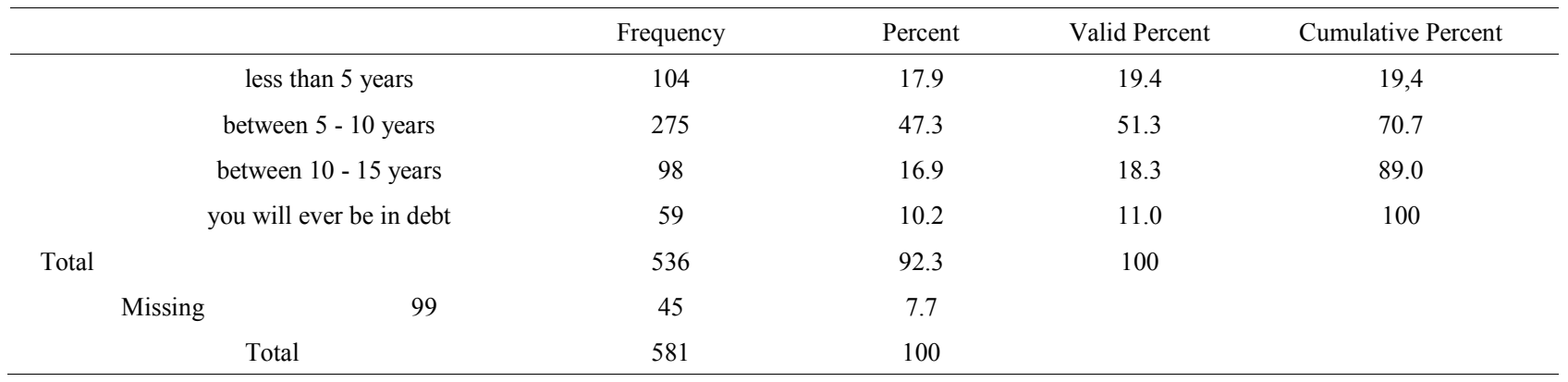


Responses in Table 9 relates to the question which tested if respondents understand both simple interest and installment amortisation. Such understanding would assist them apportion the repayment to both principal and interest charges. Table 9 indicates that only a dismal $11 \%$ correctly answered this question. Unfortunately, this performance was worse compared with that from previous studies by Lusardi and Tufano [19], Disney and Gathergood [8] and van Ooijen and van Rooij 26] where the scores were $35 \%, 45.7 \%$ and $48.3 \%$ respectively on the same question.

Table 10. Responses on the hire purchase question

\begin{tabular}{|c|c|c|c|c|c|}
\hline & \multicolumn{2}{|c|}{ Frequency } & Percent & Valid Percent & Cumulative Percent \\
\hline \multirow[t]{4}{*}{ Valid } & Option A & 105 & 19.6 & 19.6 & 19.6 \\
\hline & Option B & 147 & 25.3 & 27.4 & 46.9 \\
\hline & Both are the same & 285 & 48.9 & 53.0 & 100 \\
\hline & Total & 537 & 92.4 & 100 & \\
\hline \multirow[t]{2}{*}{ Missing } & 99 & 44 & 7.6 & & \\
\hline & Total & 581 & 100 & & \\
\hline
\end{tabular}

Responses in Table 10 relate to the question which tested the respondent's understanding of time value of money, and also APR. The better option is A. Surprisingly, only a small number of respondents (19.6\%) answered correctly. However, this performance was better compared with $6.9 \%$ scored in a study by Lusardi and Tufano [19], and 12.1\% scored in another study by van Ooijen and van Rooij [26], in a similar question. These scores show that the time value of money concept is poorly understood.

Table 11. Scorecard of the numeracy test

\begin{tabular}{|c|c|c|c|c|c|c|}
\hline \multicolumn{2}{|c|}{ Scores } & \multirow{2}{*}{$\begin{array}{c}\text { Frequency } \\
19\end{array}$} & \multirow{2}{*}{$\frac{\text { Percent }}{3.3}$} & \multirow{2}{*}{$\frac{\text { Cumm. Percent }}{3.3}$} & \multirow{2}{*}{$\begin{array}{c}\text { Mean } \\
3.393\end{array}$} & \multirow{2}{*}{$\begin{array}{c}\text { Std. Dev. } \\
1.337\end{array}$} \\
\hline Low & 0 & & & & & \\
\hline & 1 & 35 & 6.0 & 9.3 & & \\
\hline & 2 & 85 & 14.6 & 23.9 & & \\
\hline \multirow[t]{2}{*}{ Medium } & 3 & 155 & 26.7 & 50.6 & & \\
\hline & 4 & 171 & 29.4 & 80.0 & & \\
\hline \multirow[t]{3}{*}{ High } & 5 & 94 & 16.2 & 96.2 & & \\
\hline & 6 & 20 & 3.5 & 99.7 & & \\
\hline & 7 & 2 & 0.3 & 100 & & \\
\hline \multicolumn{2}{|c|}{ Total } & 581 & 100 & & & \\
\hline
\end{tabular}

Results in Table 11 found out that distribution of respondents by correct scores. In total, only two respondents answered the entire seven questions correctly. Similarly, only a minority (3.3\%) answered all the questions incorrectly. Those with professional accounting qualifications had the highest mean (3.83). This confirms Robb [24] findings that economics and finance students displayed higher financial literacy. However, One-Sample Kolmogorov-Smirnov Test found the distribution is not normal significantly ( $\mathrm{p}$-values = 0.000 ). The mean number of questions answered correctly was $3.393(48 \%)$ with a standard deviation of 1.337 . Further, results in Table 11 show that the proportion of low-score respondents were $23.9 \%$, medium-score respondents was $56.1 \%$ and the high- score respondents were $20 \%$. Using three questions Disney and Gathergood [12] got a mean of $1.86(62 \%)$ with a standard deviation of 1.02 . Yet, in another study by Liv [17] which fielded three questions, those who scored low ( 0 or 1 answer correct) were $20 \%$, moderate score (2 answers correct) were $46 \%$ and high score (3 answers correct) were $34 \%$. Clearly the respondents in this study performed worse; debt literacy is strikingly low. In fact, low debt literacy levels are not a Kenyan problem. Similar findings are reported in other surveys in Australia, US, Germany, Netherlands, Japan, New Zealand, Russia among others (Lusardi \& Mitchell, [20]). According to Finke [10], respondents who are less likely to assess interest rate, levies and penalties, and even borrowing strategies will always make sub-optimal debt decisions.

Table 12. Mean indebtedness of the respondents by numerical test score

\begin{tabular}{|c|c|c|c|c|c|}
\hline \multicolumn{3}{|c|}{ Numerical test score class } & DSR & DIR & ID \\
\hline Low & \multicolumn{2}{|c|}{ less than 3 scores } & 0.2761 & 7.8720 & 2.9786 \\
\hline Medium & \multicolumn{2}{|c|}{3 and 4 scores } & 0.3266 & 8.7439 & 3.6038 \\
\hline \multirow[t]{4}{*}{ High } & \multicolumn{2}{|c|}{ above 4 scores } & 0.2936 & 7.4337 & 2.6536 \\
\hline & \multicolumn{2}{|c|}{ Mean } & 0.3078 & 8.2720 & 3.2643 \\
\hline & \multirow[t]{2}{*}{ ANOVA } & $\mathrm{F}$ & 4.498 & 1.808 & 2.533 \\
\hline & & Sig. & 0.012 & 0.165 & 0.080 \\
\hline
\end{tabular}

Results on Table 12 established that respondents with moderate debt knowledge are more indebted by all dimensions of indebtedness. The statistical power was 
significant ( $\mathrm{p}$-values $<0.05$ ) for DSR using ANOVA. Independent Sample Kruskal-Wallis Test found the distribution of DSR (p-values $=0.043)$ and ID (p-values = 0.023 ) not the same in the three numerical test score classes. Therefore, respondents with low numeracy skills are associated with indebtedness at least by DSR measure. A study by Shicks [25] concluded that those with cognitive ability limitations were more likely to make irresponsible borrowing decisions. According to Winchester [27], higher levels of debt knowledge own or purchased has been shown to increase the likelihood of exhibiting optimal behaviours such as having adequate emergency funds. ANOVA results found that level of education and occupation had significant statistical ( $p$-value $<0.05$ ) relationship with numeracy skills. Those with high education $($ mean $=3.5)$ scored better than their counterparts while those in the financial, insurance and professional services occupations performed the best (mean =3.76). Aggregately, women performed worse than men but the ANOVA results were insignificant ( $\mathrm{p}$-value $=0.163$ ). Similarly, Lusardi [19] found that women and the lowly educated scored the worst. Similarly, de Bassa Scheresberg [15] also found that the mean for numeracy test is not significantly related to gender.

Table 13. Report on respondent's debt knowledge self-assessment

\begin{tabular}{cccccc}
\hline Rate & & Frequency & Percent & $\begin{array}{c}\text { Valid } \\
\text { Percent }\end{array}$ & $\begin{array}{c}\text { Cumulative } \\
\text { Percent }\end{array}$ \\
\hline Valid & 1 & 5 & 0.9 & 1.1 & 1.4 \\
& 2 & 7 & 1.2 & 1.7 & 2.8 \\
& 3 & 29 & 5.0 & 6.9 & 9.7 \\
& 4 & 175 & 30.1 & 41.4 & 51.1 \\
& 5 & 131 & 22.5 & 31.0 & 82.0 \\
& 6 & 57 & 9.8 & 13.5 & 95.5 \\
& 7 & 19 & 3.3 & 4.5 & 100 \\
Total & & 423 & 72.8 & 100 & \\
Missing & 99 & 158 & 27.2 & & \\
Total & & 581 & 100 & & \\
\hline
\end{tabular}

Results in Table 13 showed that majority (41.4\%) of the respondents ranked their debt knowledge neutrally. A substantial number of the respondents $(27.2 \%)$ did not want to disclose their rating or it was an oversight.

Table 14. ANOVA- Debt knowledge by self-assessment

\begin{tabular}{ccccc}
\hline & $\mathrm{F}$ & Sig. & $\begin{array}{c}\text { Spearman } \\
\text { corr. }\end{array}$ & Sig. \\
\hline Sector & 4.325 & 0.000 & -0.196 & 0.000 \\
Occupation & 2.619 & 0.012 & 0.154 & 0.002 \\
$\begin{array}{c}\text { Management } \\
\text { level }\end{array}$ & 3.594 & 0.002 & 0.135 & 0.006 \\
Education & 2.768 & 0.012 & 0.111 & 0.023 \\
\hline
\end{tabular}

From Table 14, the results revealed that respondents' self-assessed debt knowledge can be associated with sector, occupation, level of management and level of education. The respondents in the private sector performed better than those in public service. Financial, insurance and professional services' respondents had the highest mean (4.97) trailed by those in the agriculture. The relationship between debt knowledge and level of management is weak but positive meaning debt knowledge increase along the ladder of management. This perhaps is because educational qualification matters when respondents are employed and placed on the job. The relationship between debt knowledge and level of education is weak but positive meaning education contributed to increase in debt knowledge. In this study women had a lower mean (4.53) than men (4.62) but the association was statistically insignificant (p-values = 0.142). This is consistent with a study by Mottola [23] where the mean rate for women was 4.8 while that for men was 5.1. Similarly, de Bassa Scheresberg [15] also found that the mean self- assessment score is not significantly associated with gender. Self-assessed debt knowledge, also referred to as perceived debt knowledge, refers to what respondents imagine they know on debt matters. Respondents' self-assessed debt knowledge mean score is 4.58 (standard deviation $=1.088$ ). The actual debt knowledge was derived from respondents' score on the seven numeracy questions; the actual debt knowledge average score is 3.39 (standard deviation $=1.337$ ). This showed that actual and perceived knowledge do not mirror; there is substantial mismatch. This finding supports the work by de Bassa Scheresberg [15] who found that respondents gave themselves high scores, yet they did not demonstrate a similar level in numeracy and financial literacy test. The gap between actual and perceived knowledge, says Asaad [3], is valuable since it motivates learning.

Table 15. Mean indebtedness of the respondent by self-assessment scores

\begin{tabular}{|c|c|c|c|c|c|}
\hline \multicolumn{3}{|c|}{ Self-assessment classes } & \multirow{2}{*}{$\begin{array}{c}\text { DSR } \\
0.3193\end{array}$} & \multirow{2}{*}{$\begin{array}{c}\text { DIR } \\
10.7681\end{array}$} & \multirow{2}{*}{$\frac{\text { ID }}{4.2978}$} \\
\hline Low & Less th & scores & & & \\
\hline Medium & 4 and & cores & 0.2990 & 8.2001 & 3.2113 \\
\hline \multirow[t]{4}{*}{ High } & above & cores & 0.3448 & 8.4578 & 3.6380 \\
\hline & & & 0.3114 & 8.4578 & 3.4167 \\
\hline & $\begin{array}{l}\text { ANO } \\
\text { VA }\end{array}$ & $\mathrm{F}$ & 2.398 & 2.269 & 1.201 \\
\hline & & Sig. & 0.092 & 0.105 & 0.302 \\
\hline
\end{tabular}

Results on Table 15 established that respondents' self-assessed knowledge could not be statistically ( $p$-values $>$ 0.05) associated with indebtedness and its dimensions. Independent Sample Kruskal-Wallis Test found the distribution of DSR ( $\mathrm{p}$-values $=0.135)$, DIR $(\mathrm{p}$-values $=$ 0.126 ) and ID ( $p$-values $=0.371)$ the same in the three self-assessment classes. ANOVA results of self-assessment score category and aggregate over-confidence is significant ( $\mathrm{p}$-value $=0.030, \mathrm{R}=-0.121$ ) with those having lowest, more confident. This supports Asaad (2015) who found that those with high self-assessed knowledge are over-confident and are likely to engage in risky borrowing decisions such as taking cash from a credit card and making a mortgage payment late. 
ANOVA results of numerical test and self-assessment scores found they are significantly different ( $\mathrm{p}$-values $=$ $0.001, \mathrm{R}=0.169$ ). This means that self- assessment score increases as numeracy test score increases and vice versa. This is contrary to the findings of Asaad [3].

\subsection{Correlation between Debt Knowledge and Indebtedness}

From Table 16, it was found out that debt knowledge and indebtedness have a weak negative correlation $(\mathrm{R}=-0.133)$ where debt knowledge explains $1.8 \%$ of the variation in indebtedness. It follows that other factors outside debt knowledge explain $98.2 \%$ of variation in ID.
Table 16. Regression results of debt knowledge and indebtedness

\begin{tabular}{cccccc}
\hline Model & $\begin{array}{c}\text { Sum of } \\
\text { squares }\end{array}$ & df & $\begin{array}{c}\text { Mean } \\
\text { square }\end{array}$ & $\mathrm{F}$ & Sig. \\
\hline Regression & 130.725 & 1 & 130.725 & 8.65 & 0.003 \\
Residual & 7279.431 & 482 & 15.103 & 6 & \\
Total & 7410.156 & 483 & & & \\
& $\mathrm{R}=-0.133, \mathrm{R}^{2}=0.018, \Delta \mathrm{R}^{2}=0.016$ & \\
\hline
\end{tabular}

The model was found to be valid $(\mathrm{F}(1,482)=8.656$, $\mathrm{p}$-value $=0.003)$. Details of the model are found in Table 19 . The fitted model equation using the unstandardised coefficients is $\mathrm{Y}=4.626-0.496 \mathrm{X}_{1}$ while the fitted model using the standardised coefficients is $\mathrm{Y}=-0.133 \mathrm{X}_{1}$.

Table 17. Regression coefficients of debt knowledge and debt service ratio

\begin{tabular}{ccccccc}
\hline Model & Unstandardized Beta $(\beta)$ & Standard error & Standardized Beta $(\beta)$ & $\mathrm{t}$ & Sig. & VIF \\
\hline Constant & 4.626 & 0.524 & & 8.827 & 0.000 & \\
Debt knowledge & -0.496 & 0.169 & -0.133 & -2.942 & 0.003 & 1.000 \\
\hline
\end{tabular}

\subsection{Correlation between Debt Knowledge and Debt Service Ratio}

Table 18 showed that there exists a weak negative correlation $(\mathrm{R}=-0.103)$ between debt knowledge and DSR while Table 18 indicated that debt knowledge explains $1.1 \%$ of the variation in DSR. It follows that other factors outside debt knowledge explain $98.9 \%$ of variation in DSR.

Table 18. Regression results of debt knowledge and debt service ratio

\begin{tabular}{cccccc}
\hline Model & Sum of squares & $\mathrm{df}$ & Mean square & $\mathrm{F}$ & Sig. \\
\hline Regression & 0.156 & 1 & 0.156 & 5.344 & 0.021 \\
Residual & 14.589 & 501 & 0.029 & \\
Total & 14.745 & 502 & & \\
& & $\mathrm{R}=-0.103, \mathrm{R}^{2}=0.011, \Delta \mathrm{R}^{2}=0.009$ & \\
\hline
\end{tabular}

The model was found to be valid $(\mathrm{F}(1,501)=5.344$, $\mathrm{p}$-value $=0.021)$. Details of the model are found in Table 19 . The fitted model equation using the unstandardised coefficients is $Y_{1}=0.352-0.017 \mathrm{X}_{1}$ while the fitted model using the standardised coefficients is $Y_{1}=-0.103 \mathrm{X}_{1}$.

Table 19. Regression coefficients of debt knowledge and debt service ratio

\begin{tabular}{ccccccc}
\hline Model & Unstandardized Beta $(\beta)$ & Standard error & Standardized Beta( $\beta)$ & $\mathrm{t}$ & Sig. & VIF \\
\hline Constant & 0.352 & 0.022 & & 15.753 & 0.000 & \\
Debt knowledge & -0.017 & 0.007 & -0.103 & -2.312 & 0.021 & 1.000 \\
\hline
\end{tabular}

\subsection{Correlation between Debt Knowledge and Debt Income Ratio}

Analysis from Table 20 showed that there exists a weak negative correlation $(R=-0.169)$ between debt knowledge and D1R while Table 20 indicated that debt knowledge explains $2.2 \%$ of the variation in DIR. It follows that other factors outside debt knowledge explain $97.8 \%$ of variation in DIR.

Table 20. Regression results of debt knowledge and debt income ratio

\begin{tabular}{cccccc}
\hline Model & Sum of squares & df & Mean square & F & Sig. \\
\hline Regression & 443.205 & 1 & 443.205 & & \\
Residual & 19628.145 & 484 & 40.554 & \\
Total & 20071.350 & 485 & & \\
& $\mathrm{R}=-0.169, \mathrm{R}^{2}=0.022, \Delta \mathrm{R}^{2}=0.020$ & & \\
\hline
\end{tabular}


The model was found to be valid $(\mathrm{F}(1,484)=10.929$, $\mathrm{p}$-value $=0.05)$. Details of the model are found in Table 20. The fitted model equation using the unstandardised coefficients is $\mathrm{Y}_{2}=10.741-0.911 \mathrm{X}_{1}$ while the fitted model using the standardised coefficients is $\mathrm{Y}_{2}=-0.149 \mathrm{X}_{1}$.

Table 21. Regression coefficients of debt knowledge and debt income ratio

\begin{tabular}{ccccccc}
\hline Model & Unstandardized Beta $(\beta)$ & Standard error & Standardized Beta $(\beta)$ & $\mathrm{t}$ & Sig. & VIF \\
\hline Constant & 10.741 & 0.856 & & 12.546 & 0.000 & \\
Debt knowledge & -0.911 & 0.276 & -0.149 & -3.306 & 0.001 & 1.000 \\
\hline
\end{tabular}

\section{Conclusions}

It was concluded that debt knowledge has a significant effect on indebtedness, albeit minimal. Debt knowledge can also be associated with sector, occupation, level of management and level of education Therefore the government and organised finance bodies such as Institute of Certified Public Accountant of Kenya (ICPAK) and Kenya Bankers' Association (KBA) need to organise pro bono financial education open seminars or clinics so that financial information can be imparted.

\section{REFERENCES}

[1] Ajzerle, S., Brimble, M., \& Freudenberg, B. (2013). Is financial capability related to the effective use of debt in Australia? Australasian Accounting Business and Finance Journal, 7 (3), 107-126.

[2] Asaad, C. T. (2015). Financial knowledge and financial behavior: Assessing knowledge and confidence. Financial Services Review, 24 (2).

[3] Bhushan, P., \& Medury, Y. (2013). Financial literacy and its determinants. International Journal of Engineering, Business and Enterprise Applications, 4, 155-160.

[4] Bicakova, A., Prelcova, Z., \& Pasalicoca, R. (2011). Who borrows and who may not repay? Charles University, Academy of Sciences of the Czech Republic. Prague: Center for Economic Research and Graduate Education.

[5] Copur, Z. (2011). Effects of financial socialization and perceived norms on materialism: college students sample. Journal of Family and Economic Issues, 32 (4).

[6] Cynamon, B. Z., \& Fazzari, S. M. (2008). Household debt in the consumer age: Source of growth-risk of collapse. Capitalism and Society, 3(2).

[7] De Bassa Scheresberg, C. (2013). Financial literacy and financial behavior among Young adults: Evidence and implications. Numeracy, 6 (2).

[8] Disney, R., \& Gathergood, J. (2011). Financial literacy and indebtedness: New evidence for UK consumers.

[9] Finke, M. S. (2011). Behavioural determinants of household financialchioise:Three essays. University of Missouri, Unpublished PhD Thesis.

[10] Frade, L. C., \& Abreu, C. (2009). Overindebtedness and financial stress: A Comparative Study in Europe. Portuguese Science and Technology Foundation.

[11] Funfgeld, B., \& Wang, M. (2009). Attitudes and behaviour in everyday finance: evidence from Switzerland. International Journal of Bank Marketing, 27 (2), 108-128.

[12] Gathergood, J. (2012). Self-control, financial literacy and consumer over-indebtedness. Journal of Economic Psychology (33), 590-602.

[13] George, D., \& Mallery, P. (2003). SPSS for windows step by step:A simple guide and reference (4th ed.). Boston: Allyn and Bacon.

[14] Huston, S. J. (2010). Measuring financial literacy. The Journal of Consumer Affairs, 44 (2), 296-316.

[15] I. L. O. (2010). Women in labour markets: measuring progress and identifying challenges. Geneva: International Labour Office.

[16] KNBS. (2014). Kenya facts and figures, 2014. Nairobi: Kenya National Bureau of Statistics.

[17] Liv, D. (2013). Study on the drivers of over-indebtedness of microfinanceborrowers in Cambodia: An in-depth investigation of saturated areas. Cambodia Institute of Development Study

[18] Loke, V., \& Hageman, S. A. (2014). Debt literacy and social work. Journal of Financial Therapy, 4 (1).

[19] Lusardi, A. (2006). Financial literacy and financial education: Review and policy implications. Indiana State University: Network Financial institute.

[20] Lusardi, A., \& Mitchell, O. S. (2014). The economic importance of financial literacy: Theory and evidence. Journal of Economic Literature, 52 (1), 5-44.

[21] Lusardi, A. \& Tufano, P. (2009). Debt Literacy, Financial experiences, and Over-indebtedness. NBER Working Paper No. 14808.

[22] Malaysia. (2011, september 18). Household debt in Malaysia Is it sustainable? Daily Express, p. 26.

[23] Mottola, G. R. (2013). In our best interest: women, financial literacy, and credit card behavior. Numeracy, 6 (2).

[24] Robb, C. (2007). College students and credit card use:The effect of personal financial knowledge on debt behaviour. Columbia: Unversity of Missouri,.

[25] Schicks, J. (2012). The sacrifices of microborrowers in Ghana -A customer-protection perspective on measuring over-indebtedness. Brussels, Belgium: Research Institute in Mangement Science. 
[26] Van Ooijen, R., \& van Rooij, M. (2014). Mortgage risks, debt literacy and financial advice.

[27] Winchester, D. D. (2011). Three essays on the impact of financial advice. Texas Tech University,unpublished Ph.D thesis.

[28] Zakaria, R. H., Jaafar, N. I., \& Marican, S. (2012). Financial behavior and financial position: A structural equation modelling approach. Middle-East Journal of Scientific Research, 12 (10), 1396-1402.

[29] Zuroni, J., \& Lim, Y. ,. (2012). Personal financial knowledge and attitude towards credit card practices among working adults in Malaysia. International Journal of Business and Social Science, 3 (7). 